\title{
When the drugs don't work: the potential of glutamatergic antipsychotics in schizophrenia - ADDENDUM
}

Evangelos Papanastasiou, James M. Stone and Sukhi Shergill

https://oi.org/10.1192/bjp.bp.112.110999, Published online by the Royal College of Psychiatrists, 2nd January 2018

There was an oversight regarding the acknowledgement of funding from the European Research Council, which was a contractual obligation for the funding. Professor Sukhi Shergill was funded by an ERC Consolidator Award.

Evangelos Papanastasiou; James M. Stone; Sukhi Shergill

\section{Reference}

Papanastasiou E, Stone JM, Shergill S. When the drugs don't work: the potential of glutamatergic antipsychotics in schizophrenia. Br J Psychiatry 2013; 202: 91-93.

\section{Addendum}

\section{Prevalence of serum $N$-methyl-D-aspartate receptor autoantibodies in refractory psychosis - ADDENDUM}

Katherine Beck, John Lally, Sukhwinder S. Shergill, Michael A. P. Bloomfield, James H. MacCabe, Fiona Gaughran and Oliver D. Howes

https://doi.org/10.1192/bjp.bp.113.142216, Published online by the Royal College of Psychiatrists, 2nd January 2018

There was an oversight regarding the acknowledgement of funding from the European Research Council, which was a contractual obligation for the funding. Professor Sukhwinder S. Shergill was funded by an ERC Consolidator Award.

\section{Reference}

Beck K, Lally J, Shergill SS, Bloomfield MAP, MacCabe JH, Gaughran F and Howes OD. Prevalence of serum $N$-methyl-D-aspartate receptor autoantibodies in refractory psychosis. Br J Psychiatry 2015; 206: 164-165. 